\title{
Çin Yatırım Şirketi (CIC) Özelinde Finansal Küreselleşmede Devlet
}

\section{Sermayesi: Ulusal Varlık Fonları}

\section{Orhan ŞİMŞEK ${ }^{1}$}

\section{State Capital in Financial Globalization in Particular China Investment Company \\ (CIC): Sovereign Wealth Funds}

ARTICLE INFO

Article History:

Date Submitted:15.09.2016

Date Accepted: 25.12.2016

\begin{tabular}{l}
\hline JEL Classification: \\
F02 \\
F30 \\
H10 \\
O16
\end{tabular}

Keywords:

China

CIC

Sovereign Wealth Funds

Globalization

\begin{abstract}
The problems that the wave of neoliberal globalization began to face at the end of 1990s brought the debate about the role of the state in the economy back to the agenda, and in the 2000s, state centered development strategies have risen from the emerging world. In these countries, the state began to increase its weight in the national and global economy through various mechanisms. Sovereign Wealth Funds, which came at the forefront of these mechanisms, increased their function as state-owned investment instruments, which the states have used both economically and politically. In this context, one of the best examples is the China Investment Corporation (CIC).
\end{abstract}




\section{Özet}

Neoliberal küreselleşme dalgasının 1990'ların sonları itibariyle karşılaşmaya başladığı sorunlar, ekonomide devletin rolünün tartışılmasını yeniden gündeme getirirken, 2000'li yıllar itibariyle de gelişmekte olan dünyadan yükselen devlet merkezli kalkınma stratejileri ön plana çıktı. Bu ülkelerde devlet çeşitli mekanizmalarla hem ulusal hem de küresel ekonomide ağırlığını artırmaya başladı. Bu mekanizmaların başında gelen ulusal varlık fonları, devletlerin hem iktisadi hem de siyasi bağlamda kullandıkları, devlet sermayeli bir yatırım aracı olarak işlevlerini artırdı. Bu bağlamda, en iyi örneklerden biri de Çin Yatırım Şirketi (CIC) oldu.

Anahtar Kelimeler: Çin, CIC, Ulusal Varlık Fonları, Küreselleşme

\section{Giriş}

Neoliberalizmin istikrarsız yürüyüşü, devletin ekonomik yaşamdaki rolünün yeniden altının çizilmesini beraberinde getirdi. Özellikle son krizde yaşanan büyük çöküşs sonucu devlet aygıtı hem gelişmiş hem de gelişmekte olan ülkelerde kurtarıcı rol üstlendi. Bu durumla birlikte, devletin ekonomideki rolü tekrar tanımlandı. Devletin ekonomideki varlığ1 gözle görülür biçimde arttı ve bu durum-özellikle kimi gelişmekte olan ülkelerde-“devlet kapitalizmi2" olarak adlandırıldı. Söz konusu yenilenmiş süreç, küresel ekonomi politiğin de yörüngesini değiştirdi (Dixon ve Monk, 2012: 104). Bir yandan serbestleşme politikalarını "kendi özgü” koşullarla uygulayarak, küreselleşmenin getirdiği üretimin merkezsizleşmesi süreci doğrultusunda dünyanın en önemli üretim merkezi olan, diğer yandan da yine kendine özgü bir biçimde kalkınmacı devlet anlayışı olan Çin'in yükselişi, bu yörünge değişikliğinin

\footnotetext{
${ }^{2}$ Uygulama bağlamında ülkelere göre farklılık arz etse de yirmi birinci yüzyılın "yenilenmiş" devlet kapitalizminde devlet ekonomiyi ideolojik ilkeler doğrultusunda değil, siyasi ilerleme amaçlı idare etmektedir. Bu sistemde ekonomi pür olarak devlet mülkiyeti altında olmamakla birlikte, özel mülkiyetli büyük firmaların da yer aldığı, devletin özellikle anahtar sektörler olarak tabir edilebilecek, enerji, finansa, telekomünikasyon gibi sektörlerde öncü olduğu bir yapı mevcuttur. Dolayısıyla devlet kapitalizminin öncül formlarından farklı olarak, yenilenmiş devlet kapitalizmi geleneksel merkantilizmi ve dışa kapalı bir ekonomiyi öngörmez ve benimsemez. Ötesi, bu dönemin devlet kapitalizmi küreselleşmeyle tam uyumludur. Başta Çin olmak üzere, Rusya, Brezilya, Hindistan, Güney Afrika ve Körfez ülkeleri devlet kapitalizminin güncel uygulayıcıları olarak nitelendirilebilir (Bremmer, 2010; McNally, 2013).
} 
öncül nedenidir. Devlet kapitalizmi kavramının tozlu raflardan alınıp tekrar kullanılması da Çin'in yükselişi ile birebir bağlantılıdır.

1980'lerde neoliberalizm ve onun manifestosu niteliğinde olan Washington Uzlaşması'nda minimalize edilen devlet aygıtı, Post-Washington Uzlaşması'nın piyasa dostu devlet anlayışıyla kısmen de olsa yeniden iktisadi alana çekilmiş, özellikle 2008 krizi, devletin ekonomik alandaki sınırlı varlığının olumsuz sonuçlarını ortaya koymuştur. Bu kriz, modern kapitalizmi yeniden düşünme sürecini de beraberinde getirmiştir. Çünkü devlet, reel sektörden finansa, özellikle gelişmekte olan ülkeler üzerinden küresel ekonomiye yön verir hale gelmiştir. Neoliberal küreselleşme ideologları tarafindan geri plana itilen devlet, oysa küresel kapitalizmde varlığını sürdürüyordu. Başta Çin olmak üzere, Rusya, Körfez Ülkeleri, Hindistan, Brezilya gibi ülkeler devlet yönetimindeki şirketlerle küresel ekonominin yeni aktörleri olarak ön plana çıkmaktaydı.

2008 krizi sonrası hızlanan bu süreç devlet-piyasa ilişkilerini de yeniden şekillendiriyordu. Devlet artık sadece düzenleyici, denetleyici bir unsur olarak değil aynı zamanda yukarıda bahsi geçen biçimde mülkiyeti devlete ait olan kuruluşlarla da küresel anlamda bir yatırımcı konumuna geliyordu. Dolayısıyla devlet, küresel rekabet koşullarına ayak uydurarak, adeta bir özel şirket gibi çalışıyordu.

Küresel yatırımcı devletin en büyük örneği hiç kuşku yoktur ki Çin’dir. Çin'in küreselleşme stratejisinin temelini oluşturan "go global-küresele git” politikası bağlamında, başta ulusal petrol şirketleri ve bankalar olmak üzere, ağırlıklı olarak devlet mülkiyetli şirketlerle faaliyet göstermesinin yanında yeni bir yatırım aracı olarak ulusal varlık fonları (SWFs) kullanmaya başlamıştır (Şimşek, 2016).

\section{Ulusal Varlık Fonları: Kavramsal Bir Çerçeve}

Ulusal varlık fonları küresel siyasal sistemde ve dünya ekonomisinde giderek önemi artan güçlü aktörler haline gelmiş olup Lenihan (2014: 227)'a göre, bu konudaki en önemli tartışma da ulusal varlık fonlarının politik ve/veya piyasacı bir unsur olup olmadığ konusundadır. Ona göre, ulusal varlık fonları, devletin ekonomik gücünü arttıran ve aynı 
zamanda piyasacı bir mantıkla hareket eden dinamikler olduğu için bu fonlara hem siyasi hem de iktisadi misyon yüklemek olağandır. Kaldı ki ellerinde tuttuğu birikim bakımından ulusal varlık fonları, hem küresel finans, hem de küresel siyasetin orta noktasında yer almaktadır. Dolayısıyla küresel ekonomi politiğin öncül konularından biri haline gelmesi de liberal ekonomik düzende devletin gücünü arttırmış olmalarından kaynaklanmaktadır. Öyle ki, ulusal varlık fonları, devletin rekabetçi küresel ekonomide varlığını hissettirebilecek ve uzun dönemli kazançlar sağlayabilecek önemli bir unsur olarak görülmektedir. (Lenihan, 2014: 227-228).

Son birkaç yıldır-özellikle de 2000'lerin ortaları ve küresel kriz itibariyle ulusal varlık fonları, devletin ekonomideki rolünü tekrar gündeme getiren ve yeniden inşa eden bir unsur olarak ön plana çıkmıştır. Stratejik bağlamda yapılan yatırımlar, devletin küreselleşme ve finansallaşmanın getirdiği cari şartlara uyumunu ortaya sermiş olup ulusal varlık fonları, devletin küreselleşme ve finansallaşmaya uyum stratejisinin bir ürünü haline geldi. $\mathrm{Bu}$ bağlamda fonlar, sadece ekonomik bir araç değil, aynı zamanda siyasi ilerleme için de önemli bir faktör olarak küresel kapitalizmde sahne almaktadır (Haberly, 2011: 1833-1834). Bu bağlamda hem ellerinde tuttukları birikim, hem de giderek artan sayıları, neoliberalizmden devlet kapitalizmine kayışı simgeleyip simgelemediği önemli bir tartışma konusu oldu (Schwartz, 2012: 517).

Ulusal varlık fonları, küresel piyasalarda yatırım yapan ve özellikle de gelişmekte olan dünya merkezli-devlet mülkiyetindeki kurumsal yatırımcılardır. Bu terim ilk olarak Rozanov (2005) tarafından kullanılmış olup, ulusal varlık fonlarının tanımıyla ilgili bir uzlaşı bulunmamaktadır. Tablo 1'de bazı farklı ulusal varlık fonu tanımını görmek mümkündür. Ancak nasıl tanımlanırsa tanımlansın, kısaca devlet mülkiyetinde olan finansal yatırım araçları olarak betimlenebilecek olan ulusal varlık fonlarının küresel finansal manzarayı yeniden şekillendirdiği aşikar bir durumdur (Haberly, 2011: 1833).

\section{Tablo 1. Bazı Ulusal Varlık Fonları Tanımları}

IMF $\quad$ Ulusal varlık fonları çeşitli makroekonomik amaçlar için kurulmuş devlet mülkiyetli yatırım fonlarıdır. 


\begin{tabular}{|c|l|}
\hline Santiago İlkeleri & $\begin{array}{l}\text { Ulusal varlık fonları devlet mülkiyetindeki, özel amaçlı yatırım } \\
\text { fonları ya da girişimleri olarak tanımlanmaktadır. Bu fonlar } \\
\text { devlet tarafından makroekonomik amaçlar için oluşturulmuş olup } \\
\text { çeşitli yatırım stratejileri çerçevesinde, yabancı finansal } \\
\text { varlıkların da içinde olduğu çeşitli objelere yatırım gerçekleştirir. } \\
\text { Ulusal varlık fonları, genellikle ödemeler dengesi fazlalıkları, } \\
\text { resmi döviz rezervleri, özelleştirme gelirleri, mali fazlalıklar ya } \\
\text { da mal ihracatı sonucu elde edilen gelirle finanse edilir. }\end{array}$ \\
\hline OECD & $\begin{array}{l}\text { Ulusal varlık fonları doğrudan ya da dolaylı olarak devlet } \\
\text { tarafindan yönetilen, ulusal amaçları gerçekleştirmek için } \\
\text { kullanılan bir varlık havuzudur. }\end{array}$ \\
\hline Sovereign Wealth Fund \\
Institute & $\begin{array}{l}\text { Bir ulusal varlık fonu, ödemeler dengesi fazlalı̆̆1, resmi döviz } \\
\text { işlemleri, özelleştirme gelirleri, transfer ödemeleri, bütçe } \\
\text { fazlalıkları ya da kaynak ihracatından elde edilen gelirle } \\
\text { oluşturulan devlet mülkiyetindeki kuruluşlardır. }\end{array}$ \\
\hline Koch-Weser ve Haacke, & 2013 . \\
\hline
\end{tabular}

Küresel finansal manzarayı yeniden şekillendirmesinin temelinde özellikle 2008 krizi döneminde Batı finansal kurumlarının Asya ve Ortadoğu'daki ulusal varlık fonlarından epeyce yüksek sermaye akımları elde etmesi gösterilebilir. Dolayısıyla ulusal varlık fonları, bu durumun bir sonucu olarak dünyanın en büyük bankaları, özel sermayeli fonları, hedge fonlar ve diğer para kurumlarında büyük hissedarlar haline geldiler. $\mathrm{Bu}$ şekilde birer makroekonomik finansal varlıklar olmalarının yanında ulusal varlık fonları ulusal kalkınmanın ve stratejik dış yatırımın da bir aracı olma işlevi görmektedir (Haberly, 2011: 1833). Söz konusu gelişme, küreselleşmenin de bir anlamda rotasını kaydıran bir aşamanın başlamasını temsil etmektedir. "Minimal devlet" anlayışıyla 1980'lerin başından itibaren hakim olan neoliberal paradigma, devleti her ne kadar ekonomik alandan dişlıyor gibi görünse de, gelişmekte olan ülkeler üzerinden yükselen yeni nesil devlet kapitalizmi, devletin girişimci olarak ekonomide yer aldığı bir düzenin habercisi oldu ve bunun da en önemli araçlarından biri olarak da ulusal varlık fonları büyük önem kazandı.

Devlet girişimciliğinin önemli bir örneği olarak ulusal varlık fonlarının yükselişi, küresel finansal sistemle birlikte devlet egemenliğinin yeniden inşasını getiren bir süreç oldu. Artık özellikle ulusal varlık fonlarıyla yatırım yapan devletler sadece belli bir toprak parçasını değil, bu fonlar aracılığıyla başka devletlerin toprakları içindeki kurum ve kuruluşlar ile 
sahaları da yönetir oldu. Dolayısıyla bu süreç devlet egemenliğinin deterritoryalizasyonu yani alansızlaşması olarak kabul edilebilir. Devlet tasarruflarının ve devlet birikimlerinin bu fonlar aracılığıyla alansızlaşması devlet güdümünde kapitalizmin alanını genişletti (Haberly, 2011: 1834).

\begin{tabular}{|c|c|c|c|c|}
\hline Ülke & Ulusal Varlık Fonu & $\begin{array}{c}\text { Varlık } \\
\text { (milyar dolar) }\end{array}$ & Kuruluş & Fon Kaynağı \\
\hline Norveç & $\begin{array}{lll}\text { Government } & \text { Pension } & \text { Fund- } \\
\text { Global } & & \end{array}$ & 885 & 1990 & Petrol \\
\hline Çin & China Investment Corporation & 813.8 & 2007 & Mamul dış1 \\
\hline $\begin{array}{l}\text { BAE-Abu } \\
\text { Dabi }\end{array}$ & $\begin{array}{l}\text { Abu Dhabi Investment } \\
\text { Authority }\end{array}$ & 796 & 1976 & Petrol \\
\hline $\begin{array}{l}\text { Suudi } \\
\text { Arabistan }\end{array}$ & SAMA Foreign Holdings & 598.4 & - & Petrol \\
\hline Kuveyt & Kuwait Investment Authority & 592 & 1953 & Petrol \\
\hline Çin & SAFE Investment Company & 474 & 1997 & Mamul diş1 \\
\hline $\begin{array}{l}\text { Çin-Hong } \\
\text { Kong }\end{array}$ & $\begin{array}{l}\text { Hong Kong Monetary Authority } \\
\text { Investment Portfolio }\end{array}$ & 442.4 & 1993 & Mamul diş̧1 \\
\hline Singapur & $\begin{array}{l}\text { Government of Singapore } \\
\text { Investment Corporation }\end{array}$ & 350 & 1981 & Mamul diş1 \\
\hline Katar & Qatar Investment Authority & 335 & 2005 & $\begin{array}{ll}\text { Petrol ve } & \text { vaglgaz }\end{array}$ \\
\hline Çin & National Social Security Fund & 236 & 2000 & Mamul diş1 \\
\hline BAE-Dubai & $\begin{array}{l}\text { Investment Corporation of } \\
\text { Dubai }\end{array}$ & 196 & 2006 & Mamul diş̧1 \\
\hline Singapur & Temasek Holdings & 193.6 & 1974 & Mamul dış1 \\
\hline $\begin{array}{l}\text { Suudi } \\
\text { Arabistan }\end{array}$ & Public Investment Fund & 160 & 2008 & Petrol \\
\hline $\begin{array}{l}\text { BAE-Abu } \\
\text { Dhabi }\end{array}$ & Abu Dhabi Investment Council & 110 & 2007 & Petrol \\
\hline
\end{tabular}




\begin{tabular}{|l|l|c|l|l|}
\hline Avusturalya & Australian Future Fund & 95 & 2006 & Mamul dişı \\
\hline Kaynak: http://www.swfinstitute.org/sovereign-wealth-fund-rankings/ (2016 Eylül itibariyle \\
güncellenmiş veriler) Eylül 2016 itibariyle SWFI'de görünen 78 ulusal varlık fonunun toplam \\
değeri 7, 395.7 milyar dolar
\end{tabular}

Devletin birikmiş varlığını özel finansal piyasalarda değerlendiren ulusal varlık fonlarının sayısı 2000 yılından itibaren hem sayılarının hem de toplam yatırımlarının artış göstermesi küresel ekonomik manzarada önemli değişikliklere neden oldu (Tablo 2, Tablo 3).

\begin{tabular}{|c|c|c|c|}
\hline Yıl & Yatırım Sayısı & Yatırım Miktarı (Milyar Dolar) & \\
\hline 2000 & 27 & 1.8 & \\
\hline 2001 & 20 & 0.5 & \\
\hline 2002 & 34 & 1.3 & \\
\hline 2003 & 39 & 2.1 & \\
\hline 2004 & 53 & 5.7 & \\
\hline 2005 & 93 & 11.5 & \\
\hline 2006 & 92 & 25.2 & \\
\hline 2007 & 138 & 77.7 & \\
\hline 2008 & 173 & 111.7 & \\
\hline 2009 & 158 & 88.2 & \\
\hline 2010 & 210 & 47.6 & \\
\hline 2011 & 250 & 82.6 & \\
\hline 2012 & 270 & 58.4 & \\
\hline 2013 & 173 & 49.3 & \\
\hline 2014 & 133 & 68.6 & \\
\hline 2015 & 186 & 48.0 & \\
\hline \multicolumn{4}{|c|}{ Sovereign Investment Lab Annual Report, 2016} \\
\hline
\end{tabular}

Yirminci yüzyılın finansal tarihi Anglo-Amerikan finans kurumları tarafindan temsil edilirken, yirmi birinci yüzyılda piyasaya ulusal varlık fonları gibi yeni oyuncular eklenmiş 
oldu. Bu bağlamda, ulusal varlık fonlarının yükselişi yeni bir çalışma alanı yarattı. Ampirik olarak bu fonların, modern kapitalizmin, küresel bütünleşmenin ve devlet egemenliğinin dinamiklerini değiştiren bir unsur halini almış olması da, onları küresel bağlamda dikkate değer birer devlet yatırım aracı yapmaktadır (Dixon ve Monk, 2012).

Sun, Li vd (2014), cari dönemde ulusal varlık fonlarının olduğu ülkeleri üçe ayırmaktadır.

1. Arap Petrol Üreticisi Ülkeler (Abu Dabi, Fas, Dubai, Kuveyt, Libya, Katar, Suudi Arabistan

2. Arap Olmayan Petrol Üreticisi Ülkeler (Norveç, Rusya)

3. Gelişmekte Olan Doğu Asya Ülkeleri (Çin, Hong Kong, Singapur)

1970’lerdeki birinci petrol krizi sonrasında büyük petrol ihracatçısı ülkeler, kendi ulusal varlık fonlarını kurdular. Bunun nedeni de petrol kaynaklarının azalabileceği endişesidir. 1990'larda ise gelişmekte olan Asya ülkeleri hızlı kalkınmalarını takiben döviz rezerv fazlası elde edip bu ülkeleri izledi. Norveç, Rusya, Suudi Arabistan, Kuveyt, Abu Dabi, Katar ve Alaska'nın ulusal varlık fonlarının sermayesi petrol gelirlerinden karşılanmaktayken, Çin ve Singapur gibi ülkeler mal ihracatına bağlı olarak ortaya çıkan dış ticaret fazlalarını bu fonlarda kullanmaktadır. Sermaye kaynağı farklı olsa da hepsinin ortak yanı devlet mülkiyetinde olmalarıdır (Sun, Li vd, 2014: 655).

Ulusal varlık fonları siyaset ve finansın kavşak noktasında olduğundan beri, devlet otoritesinin piyasadaki varlığının başka bir türünü işaret etmektedirler. Bu bağlamda ulusal varlık fonları, dünyanın en önemli güç aracı olarak tanımlanabilir. Bu durum ulusal varlık fonlarının yatırım yaptığı ülkelerde finansal korumacılığa yönelişe sebep oldu. Çünkü bu fonlar, jeopolitik gücün dağılımında bir kayışa sebep olmaktadır. Özellikle de Çin ulusal varlık fonlarının enerji yatırımları Çin'in jeopolitik amaçları için bir araç olarak görülmektedir (Sun, Li vd, 2014). 


\section{Çin ve Ulusal Varlık Fonları: Çin Yatırım Şirketi (CIC)}

Çin'in cari politik ekonomi yapısı melez, rekabet odaklı bir devlet destekli kapitalizm çeşidi olarak nitelenebilir. Geniş devlet müdahaleciliğinin, küresel ekonomik süreç ile derin bir bütünleşme içerisine girdiği yeni nesil devlet kapitalizmi türü olarak da adlandırmak mümkündür (ten Brink, 2014: 38). Çünkü Çin politik ekonomisi son on y1llarda finans odaklı küresel ekonomiyle bütünleşmiş durumdadır. Bu duruma Çin devleti de kendine özgü refleks ve kısıtlarla cevap verdi. Bu kısıtlarla amaçlanan, küreselleşmeyle uyum sonucu ele gelen firsatları sürdürmek ve yeni coğrafi bölgelerde yeni piyasalara açılmaktır. Yeni piyasalar ve yeni coğrafyalara açılırken de hem ulusal finansal sistemin ve devlet mülkiyetli şirketlerin yeniden inşası, hem de neoliberal ilkelere kapitalist araçlar bağlamında "seçici uyum" ve bu çerçevede devlet mülkiyetli şirketler ve ulusal varlık fonlarıyla küresel kapitalizmde var olma hedefleri korelasyonlu bir şekilde belirlenmiştir (Lim, 2010: 678). Ortaya çıkan durum da neoliberal küresel kapitalizme devlet sermayesi bağlamında uyum sağlayan düalist bir yapıdır. $\mathrm{Bu}$ süreç, neoliberal küreselleşmeyi devletçi küreselleşmeye götürebilecek stratejik bir dönemeci ifade etmektedir. Çin ekonomik düzeni McNally (2013) tarafından da yenilenmiş devlet kapitalizmi olarak betimlenmektedir.

Çin ekonomisinin dışa açılmasıyla beraber artan uluslararası ticaret bağları, ülkenin büyük döviz rezervleri elde etmesini sağladı. Dolayısıyla Çin bürokrasisi hem bu rezervlerini değerlendirmek, hem de küreselleşme politikası bağlamında dış yatırımlarını kuvvetlendirmek adına 2007 y1lında China Investment Corporation (CIC) adlı ulusal varlık fonunu kurdu. O zamana değin, halihazırda ulusal varlık fonuna sahip olan ülkeler ya büyük petrol ihracatçıları ya da görece daha küçük ihracat odaklı sanayileşmiş ülkelerdi. Çin'in dünyanın üretim üssü haline gelmesi ve dünyanın en büyük ihracatçısı konumunda olması başta enerji olmak üzere tüm doğal kaynaklara olan ihtiyacını arttırdı. Bu bağlamda ulusal varlık fonları Çin için stratejik bir yatırım aracı oldu (Liew ve He, 2010).

Finans Bakanlığg tarafından 1.55 trilyon RMB değerinde özel bonoların verilmesiyle kurulan CIC, tümüyle devlet mülkiyetli bir şirket olup, CIC'nin küresel bir ulusal varlık fonu olarak temel işlevi 200 milyar dolarlık döviz rezervlerini stratejik olarak belirlediği yatırım 
ilkeleri (Tablo 4) doğrultusunda değerlendirmek ve bu değerlendirişi uzun dönemde yüksek getiri olarak döndürebilmektir (Sun, Li, vd., 2014: 656).

\section{Tablo 4. CIC Yatırım İlkeleri}

CIC ticari olarak yatırım yapar. Hedefi, hissedarı için kabul edilebilir risk toleransı dahilinde azami getiri elde etmektir.

CIC, finansal bir yatırımcı olup portföyündeki şirketlerin kontrolünü gözetmez.

CIC, Çin'in ve alıcı ülkelerin veya bölgelerin kanun ve yönetmeliklerine uymak ve kurumsal sosyal sorumluluklarını titizlikle yerine getirmekten sorumlu bir yatırımeıdır.

CIC, hem karar verme hem de yatırım faaliyetlerinde ihtiyatlı ve disiplinli bir yaklaşım sağlamak için bir varlık tahsisatı çerçevesinde derinlemesine araştırmaya dayalı yatırımlar sürdürmektedir.

CIC Annual Report 2015

200 milyar dolarlık rezervlerin yarısından fazlası CIC'nin küresel yatırımlarına ayrılmış ve bu küresel yatırımlar CIC International ve CIC Capital adlı alt birimler tarafından yapılmaktadır. Bununla birlikte fonun ulusal yatırımları Central Hujin tarafindan yapılmaktadır. CIC International denizaşırı yatırımları kontrol etmek ve yapmak için kurulmuştur. Aralık 2011'de 30 milyar dolar enjekte edilerek dış yatırımları çeşitlendiren bir araç rolünün güçlendirilmesi hedeflendi. Bu bağlamda CIC, özellikle enerji, doğal kaynaklar, gayrimenkul ve altyapı sektörlerinde doğrudan yatırımlar yapmaya başladı (Sun, Li, vd., 2014: 657). Central Hujin de iç finansal yapıyı güçlendirmeye çalışan ve bankalara destek veren (Tablo 5) stratejik yatırımlar gerçekleştiren devlet finans holdingi olarak işlem gerçekleştirmektedir (Overbeek, 2012: 154).

\begin{tabular}{|l|l|}
\hline $\begin{array}{l}\text { Tablo 5. Central Hujin'in Çin'in Önde Gelen Bankalarında Sahip Olduğu Portföy } \\
\text { Oranları, } \%\end{array}$ \\
\hline China Development Bank & 47.63 \\
\hline Industrial and Commercial Bank of China & 35.12 \\
\hline
\end{tabular}




\begin{tabular}{|l|c|}
\hline Agricultural Bank of China & 40.28 \\
\hline Bank of China & 65.52 \\
\hline China Construction Bank & 57.26 \\
\hline CIC Annual Report 2014
\end{tabular}

CIC'nin kuruluşu zaten Çin'in geniş küreselleşme politikası çerçevesinde sermaye birikimini çeşitlendirmek bağlamında bir stratejidir (Sun, Li, vd., 2014: 657). Bu bağlamda CIC, içeride bir kalkınma bankası, dışarıda ise maceracı bir ulusötesi yatırımcı olarak nitelenebilir (Schwartz, 2012: 526).

Çin ulusal varlık fonları ülkenin ekonomik yükselişinin bir neticesi olup, ülkenin ulusötesi-denizaşırı yatırımlarını geliştirmek adına kullanılan bir devlet stratejisidir. 1978'den beri süregelen reform ve dışa açılma serüveni ile Çin'in GDP'si ihracat odaklı büyüme modeli çerçevesinde hızla büyüdü. Bunun sonucunda küresel ekonomiyle daha derin entegrasyon ve dış yatırımların artışı da beraberinde geldi. Onuncu Beş Yıllık Plan (2001-2005)'de belirlenen küresele yönel stratejisi bağlamında dış yatırımlara yönelen devlet mülkiyetli ve özel mülkiyetli şirketler gibi, ulusal varlık fonları da yabancı şirket ve kuruluşlardan, özellikle de hem iktisadi hem de politik anlamda kazanç sağlayacak olan enerji sektöründeki kuruluşlardan hisseler satın almaya başladı. Bu süreç özellikle de 2008 krizi sonrası hizlanarak devam etti (Koch-Weser ve Haacke, 2013: 10-11).

Çin'de ulusal varlık fonları, ülkenin ekonomik yükselişinin bir ürünü ve dış yatırımları geliştirmek için kullanılan bir devlet stratejisidir. CIC, bunların en önündeki ve kuruluşundan 2012'ye yaklaşık beş yılda varlığını iki buçuk kat arttıran bir ulusal varlık fonudur. Birçok ülke bir ya da iki tane varlık fonuna sahipken Çin dört tane ulusal varlık fonuna sahiptir: CIC, SAFE Investment Company, National Social Security Fund (NSSF) ve China-Africa Development Fund (CADF). Bu fonların her biri devletin farklı alanlardaki yatırım amaçları için kurulmuştur (Tablo 6) (Koch-Weser ve Haacke, 2013: 4). Hem deniz aşırı yatırımları, hem de ülkenin mevcut finansal kurumları ile devlet mülkiyetli şirketlerine verdiği destekler ile döviz rezervleri kökenli olması ve doğrudan Devlet Konseyi tarafından idare edilmesi CIC'nin konumunu güçlendirmektedir. 


\begin{tabular}{|c|c|c|c|c|}
\hline & $\begin{array}{l}\text { SAFE Investment } \\
\text { Company }\end{array}$ & $\begin{array}{l}\text { National Social } \\
\text { Security Fund }\end{array}$ & $\begin{array}{l}\text { China Investment } \\
\text { Corporation } \\
\text { (CIC) }\end{array}$ & $\begin{array}{l}\text { China-Africa } \\
\text { Development } \\
\text { Fund (CADF) }\end{array}$ \\
\hline Kuruluş Y1lı & 1997 & 2000 & 2007 & 2007 \\
\hline $\begin{array}{l}\text { Varlık (Eylül } \\
2016 \text { itibariyle, } \\
\text { milyar dolar) }\end{array}$ & 474 & 236 & 813.8 & 5 \\
\hline Kuruluş Yeri & Hong Kong & Pekin & $\begin{array}{l}\text { Pekin, Toronto, } \\
\text { Hong Kong }\end{array}$ & Pekin \\
\hline Resmi Amaçlar & $\begin{array}{l}\text { ABD dolarının } \\
\text { değerindeki } \\
\text { dalgalanmaların } \\
\text { neden olacağı } \\
\text { riskleri azaltmak } \\
\text { adına döviz } \\
\text { rezervlerini } \\
\text { çeşitlendirmek. } \\
\text { Öncelikli olarak } \\
\text { da düşük riskli } \\
\text { yabancı varlıklara } \\
\text { yönelmek. }\end{array}$ & $\begin{array}{l}\text { Gelecekteki } \\
\text { sosyal güvenlik } \\
\text { harcamaları } \\
\text { finanse etmek } \\
\text { amacıyla merkezi } \\
\text { hükümet } \\
\text { tarafından } \\
\text { biriktirilen rezerv } \\
\text { fonu. Amaç, } \\
\text { emeklilik } \\
\text { fonlarının reel } \\
\text { değerini korumak } \\
\text { ve artırmaktır. }\end{array}$ & $\begin{array}{l}\text { Yatırımlardan } \\
\text { gelen getirilerin } \\
\text { maksimizasyonu } \\
\text { ile döviz } \\
\text { rezervlerini } \\
\text { çeşitlendirmek. }\end{array}$ & $\begin{array}{l}\text { Sübvansiyon ve } \\
\text { kredi yoluyla } \\
\text { Afrika } \\
\text { Ekonomisini } \\
\text { kalkındırmak. }\end{array}$ \\
\hline $\begin{array}{ll}\text { Devlet } & \text { adına } \\
\text { sahibi } & \end{array}$ & $\begin{array}{l}\text { People's Bank of } \\
\text { China (PBOC) }\end{array}$ & $\begin{array}{l}\text { National Council } \\
\text { for } \quad \text { Social } \\
\text { Security Fund }\end{array}$ & State Council & $\begin{array}{l}\text { China } \\
\text { Development } \\
\text { Bank }\end{array}$ \\
\hline
\end{tabular}

Çin için ulusal varlık fonları hem kalkınma politikaları bağlamında sanayileşmeyi finanse edecek hem de devlet tasarruflarını ulusal ve küresel bağlamda verimli yatırımlara dönüştürecek bir araç olarak önem taşımaktadır (Liew ve He, 2010). Dolayısıyla ulusal varlık fonları, devletin jeopolitik güç kazanması için de önemli bir araçtır. Çünkü özellikle deniz aşırı yatırımlar başta enerji sektörü üzerine yoğunlaşmakta ve oldukça aktif biçimde sürmektedir.

CIC'nin kuruluşu, Çin'in küreselleşme politikası bağlamında sermaye birikim stratejilerini çeşitlendirme gayretinde olduğunu göstermektedir. Dolayısıyla, küreselleşme 
politikası CIC'nin doğasında olan ve döviz rezervlerini yararlı hale getirmek anlamında kaçınılmaz bir süreçtir. Yukarıda da ifade edildiği üzere CIC, ticari işlemleri doğrudan yapmakla kalmamakla beraber, aynı zamanda Çin şirketlerinin- özellikle de devlet mülkiyetli şirketlerin- küreselleşme politikalarına dolaylı olarak destek sağlıyor. Ayrıca CIC'nin Çin Devlet Konseyi bünyesinde olması, aynı devlet mülkiyetli şirketlerde olduğu gibi, devletin doğrudan ulusal varlık fon yatırımlarının coğrafyasını ve tercihlerini etkilediğini ifade etmektedir. Bu bağlamda hem devlet mülkiyetli şirketlerin hem de ulusal varlık fonlarının başta enerji sektörü olmak üzere yaptığı yatırımlar Çin'in küreselleşme politikasının bir parçasıdır. Enerji özelindeki yatırımlar, küreselleşme politikasıyla olduğu kadar enerji güvenliğiyle de alakalıdır. 2008 krizinin olumsuz etkilerine karşın CIC küresel portföyünü 2009'da yüzde 11.7 arttırdı (Tablo 7). Bu bağlamda hem küresel portföy artışını sürdürmek, hem de ülkenin artan enerji talebinin karşılanacağı enerji arz miktarını garantiye alacak ve böylelikle enerji güvenliğini sağlayacak yatırımlar yapmayı hedefledi ve yaptığı doğrudan dış yatırımların çoğu enerji sektörüyle alakalı oldu (Sun, Li, vd., 2014: 657). Özellikle Asya finans krizi sonrasında birçok Güneydoğu Asya ülkesi gibi döviz rezervleri biriktiren Çin, bu döviz rezervlerine öncül olarak, olası küresel ekonomik bunalımlardan ülkeyi koruyacak bir işlev edinme rolü biçti ve ulusal varlık fonları da bu rolün uygulayıcısı olarak ekonomik düzende yer aldı (Nolan, 2012: 141).

\begin{tabular}{|c|c|}
\hline \multicolumn{2}{|c|}{ Tablo 7. CIC'nin küresel portföy artış oranları, \% } \\
\hline 2008 & -2.1 \\
\hline 2009 & 11.7 \\
\hline 2010 & 11.7 \\
\hline 2011 & -4.3 \\
\hline 2012 & 10.60 \\
\hline 2013 & 9.33 \\
\hline 2014 & 5.47 \\
\hline 2015 & -2.96 \\
\hline CIC Annual Report 2015
\end{tabular}


Çin ekonomisinin gelişmesiyle birlikte artan enerji ithalatına bağımlılık, enerji güvenliği önünde önemli bir engel teşkil etmektedir. Dolayısıyla enerji sektörü Çin için kritiktir ve enerji güvenliğini sağlama hedefi de öncül politika tercihlerindendir. Enerji kıtllğ 1 tehlikesi karşısında devletin dünya genelinde enerji sektörünü kontrol etmesi de enerji güvenliği meselesi ile alakalıdır. Enerji güvenliği, enerji arzının düzenli bir biçimde ve uygun bir fiyattan sürekli olarak gerçekleştirilmesi anlamına gelmektedir (Sun, Li vd, 2014: 659). Bu bağlamda CIC, ülkenin enerji kaynak arzını artıracak ve daha istikrarlı hale getirecek yatırımlara yönelmiştir. Bu noktada sadece doğrudan yatırım yapmakla kalmayıp, Çin şirketleri tarafından yapılan dış yatırımları da desteklemektedir. Örneğin Huawei ve ZTE'nin Avrupa ve ABD’ye açılımı konusunda maddi destek sağlamıştır. Ayrıca Pekin hükümeti CIC'i ulusal ekonomik modernizasyonu desteklemek ve uygulanan politikaları sağlamlaştırmak için kullanmaktadır. CIC'nin ulusal bankalara yaptığı yatırımlar, özellikle devletin kredi arzını kontrol etme şansını güçlendiriyor (Blanchard, 2011: 40-41; Blanchard, 2014: 164).

Çin ulusal varlık fonları, ülkenin küreselleşme politikasının yeni unsurları olarak hammadde ve enerji güvenliği için kilit konumda yer almaktadır. Özellikle CIC'nin 27,3 milyar dolarlık bir küresel enerji yatırımı mevcut bu yatırımların yaklaşık yüzde 60'ını ise Avrupa çekmektedir. Bu da Çin'in ekonomik büyüme için enerji sektörünü mihenk taşı olarak gördüğünü göstermektedir (Tablo 8). Çünkü ekonomik büyüme ile birlikte artan enerji ve doğal kaynak ihtiyacı, ülkenin dış politikasını da belirleyen bir unsur haline geldi (Kaminski, 2017).

\begin{tabular}{|c|c|c|c|c|c|}
\hline Şirket & Ülke & Yil & $\begin{array}{l}\text { Yatırım } \\
\text { Miktarı } \\
\text { (Milyon dolar) }\end{array}$ & Sektör & Mülkiyet \\
\hline Tek Resources Limited & Kanada & 2009 & 1500 & $\begin{array}{l}\text { Madencilik ve } \\
\text { mineral }\end{array}$ & 17.2 \\
\hline JSK $\quad$ KazMunaiGas & Kazakistan & 2009 & 940 & Petrol ve & 10.6 \\
\hline
\end{tabular}




\begin{tabular}{|c|c|c|c|c|c|}
\hline Exploration Production & & & & doğalgaz & \\
\hline Nobel Oil Group LTD & Rusya & 2009 & 270 & $\begin{array}{ll}\text { Petrol } & \text { ve } \\
\text { doğalgaz }\end{array}$ & 45 \\
\hline PT Bumi Resources Tbk & Endonezya & 2009 & 1900 & $\begin{array}{l}\text { Termal kömür } \\
\text { üretimi }\end{array}$ & $\mathrm{N} / \mathrm{A}$ \\
\hline Noble Group Limited & Singapur & 2009 & 858 & Doğal kaynak & 14.9 \\
\hline $\begin{array}{l}\text { SouthGobi Energy } \\
\text { Resources Limited }\end{array}$ & Kanada & 2009 & 500 & $\begin{array}{l}\text { Kömür, maden } \\
\text { keşif }\end{array}$ & $\mathrm{N} / \mathrm{A}$ \\
\hline $\begin{array}{l}\text { GCL-Poly Energy } \\
\text { Holdings Limited }\end{array}$ & $\begin{array}{l}\text { Hong } \\
\text { Kong }\end{array}$ & 2009 & 717 & $\begin{array}{l}\text { Yenilenebilir } \\
\text { enerji }\end{array}$ & 20.1 \\
\hline AES & $\mathrm{ABD}$ & 2010 & 1581 & Power ve utility & 15 \\
\hline Penn West & Kanada & 2010 & 416 & $\begin{array}{ll}\text { Petrol } & \text { ve } \\
\text { doğalgaz }\end{array}$ & 5 \\
\hline $\begin{array}{l}\text { Peace River Oil } \\
\text { Partnership }\end{array}$ & Kanada & 2010 & 329 & $\begin{array}{ll}\text { Petrol ve } & \text { ve } \\
\text { doğalgaz }\end{array}$ & 45 \\
\hline Chesapeake Energy & $\mathrm{ABD}$ & 2010 & 200 & $\begin{array}{ll}\text { Petrol } & \text { ve } \\
\text { doğalgaz } & \end{array}$ & $\mathrm{N} / \mathrm{A}$ \\
\hline BUMA & Endonezya & 2010 & 73 & Maden servisi & 8 \\
\hline $\begin{array}{l}\text { AES-VCM Mong Duong } \\
\text { Power Company Limite }\end{array}$ & Vietnam & 2011 & 93 & Power & 19 \\
\hline Shanduka & $\begin{array}{l}\text { Güney } \\
\text { Afrika }\end{array}$ & 2011 & 2 milyar rand & Maden & 25.8 \\
\hline $\begin{array}{l}\text { Cheniere } \quad \text { Energy } \\
\text { Partners }\end{array}$ & $\mathrm{ABD}$ & 2011 & 850 & Doğalgaz & 10 \\
\hline GDF Suez & Fransa & 2011 & 3150 & Keşif üretim & 30 \\
\hline Sunshine Oilsands Ltd. & Kanada & 2012 & $\begin{array}{l}150 \text { milyon } \\
\text { kanada doları }\end{array}$ & $\begin{array}{ll}\text { Petrol } & \text { ve } \\
\text { Doğalgaz } & \end{array}$ & 1.43 \\
\hline EP Energy & $\mathrm{ABD}$ & 2012 & 300 & Enerji & 9.9 \\
\hline Polyus Gold & Rusya & 2012 & 425 & Maden & 5 \\
\hline
\end{tabular}




\section{Sonuç}

Ulusal Varlık Fonları, devletin 2000'li yıllar itibariyle ekonomideki rolünün aktif bir biçimi olarak, uluslararası iktisat ve küresel ekonomi politikte üzerine bolca tartışma yürütülen bir konu halini almıştır. Devletler daha önceleri bu fona benzer araçlar kullanmış olsa da modern anlamda ulusal varlık fonlarının kökeni 1953 yılında Kuveyt'in yatırım fonu kurmasına kadar gitmektedir. Ancak, bu fonlar 2000'li yıllarda hız kazanmış olup, günümüzde finansal ekonomide ve yatırım süreçlerinde oldukça aktif konumdadırlar. 2000'lere doğru Batıda Post-Washington Uzlaşmasıyla başlayan etkin-piyasa dostu devlet algısı, özellikle Doğu ülkelerinde girişimci ve yatırımcı devlet olarak tezahür gösterdi. Bunun en büyük örneği de, 1978 yılı itibariyle piyasa reformları uygulayarak küresel kapitalizme eklemlenen ve kendine özgü kalkınma modeli çerçevesinde bu eklemlenmeyi sürdüren Çin'dir. Başta enerji sektörü olmak üzere stratejik sektörlerde kamu girişimciliğine öncelik tanıyan Çin, bu sektörlerdeki devlet şirketlerini küreselleşme stratejisi bağlamında dişa açmıştır. Bunla birlikte dünyanın üretim merkezi konumunda olmasının getirdiği ihracat gelirleri ile büyük döviz rezervlerine ulaşan ülke, bu rezervleri ulusal varlık fonları ile değerlendirmeyi tercih etti.

Halihazırda dört adet ulusal varlık fonuna sahip olan Çin'in en büyük fonu 2007 yılında kurulan Çin Yatırım Şirketi (CIC)'dir. CIC hem dışarıda yatırım yapmakla yükümlü olup hem de kendisine bağlanan Central Hujin aracılığıyla ülkenin finansal mimarisini kontrol etmektedir. Dış yatırımda ise, artan sanayileşme ve nüfusun getirdiği büyük enerji ihtiyacını karşılayacak şekilde yatırımlara yönelmiş, böylelikle ülkenin enerji güvenliğini sağlamasında katkıda bulunmuştur. CIC ayrıca, gayrimenkul, altyapı ve bilgi teknolojileri alanında da yatırımlara yönelmekte ve Çin'in küresel faaliyet gösteren diğer şirketlerine finansal olarak katkı sağlamaktadır.

Devlet sermayesinin aktif bir biçimde ekonomik sürece sokulmasının yolu olan ulusal varlık fonları, sadece ekonomik değil, küresel kapitalizmde söz sahibi olma, çok kutuplu bir düzen oluşturma çabaları doğrultusunda Çin'in stratejik ve jeopolitik bağlamda kullandığı bir araçtır. Piketty (2015)'nin neokoloniyalizm aracı olarak nitelediği bu fonların, özellikle gelişmekte olan ülkelerden çok gelişmiş ülkelerde yatırım alanına sahip olması da Batı 
dünyasında fon sahibi Doğu ülkelerinin etki alanını güçlendirmenin de bir aracısı konumundadir.

Neoliberalizmin giderek zayıflaması, Çin ve benzer ülkelerin uyguladığı devlet öncülüğünde kalkınma modelinin güçlenmesi ve devlet sermayesinin ekonomide yayılması, sadece gelişmekte olan ülkeler için değil, gelişmiş ülkeler için de önemli bir süreçtir. Ülkelerarası artan iktisadi ve siyasi rekabet dünya ekonomisinde devletlerin aktif olarak sahnede olacağını göstermektedir. Bu bağlamda, kısa vadede ulusal varlık fonları ve benzer devlet sermayeli yatırım araçlarının sayısının yükselmesi şaşırtıcı olmayacaktır.

\section{Kaynakça}

Blanchard, Jean-Marc F. (2011), “China’s Grand Strategy and Money Muscle: The Potentialities and Pratfalls of China's Sovereign Wealth Fund and Renminbi Policies", Chinese Journal of International Politics, 4(1), 31-53. https://doi.org/10.1093/cjip/por002

Blanchard, Jean-Marc F. (2014). "The China Investment Corporation: Power, Wealth or Something Else?” CIJ, 12(3), 155-175.

Bremmer, Ian (2010), The End Of The Free Market. New York: Portfolio.

CIC. 2014. Annual Report.

CIC. 2015. Annual Report.

Dixon, Adam D. and Ashby H.B. Monk (2012), Rethinking the sovereign in sovereign wealth funds. Transactions of the Institute of British Geographers, 37 (1), 104-117.

Haberly, Daniel (2011), "Strategic Sovereign Wealth Fund Investment and the New Alliance Capitalism: A Network Mapping Investigation”, Environment and Planning, 43, $1833-1852$.

Kaminski, Thomasz (2017), "Sovereign Wealth Fund Investments in Europe as an Instrument of Chinese Energy Policy”, Energy Policy, 101, 733-739. 
Koch-Weser, I., Hacke, O. (2013), “China Investment Corporation: Recent Developments in Performance, Strategy, and Governance", U.S.-China Economic and Security Review Commission.

Lenihan, Ashley T (2014), “Sovereign Wealth Funds And The Acquisition Of Power”, New Political Economy, 19(2). 227-257.

Liew, Leong H., He, Liping (2012), “Operating İn An Inharmonious World: China Investment Corporation", Journal of the Asia Pacific Economy, 17 (2), 253-267.

Lim, Kean Fan (2010), On China's Growing Geo-economic Influence and the Evolution of Variegated Capitalism. Geoforum, 41(5), 681.

McNally, Christopher A. (2013), "How Emerging Forms of Capitalism Are Changing The Global Economic Order", Analysis From The East-West Center, No: 107.

Nolan, Peter (2013), Is China Buying The World? U.S.A: Polity Press.

Overbeek, Henk (2012), “Sovereign Wealth Funds in the Global Political Economy: The Case of China", in Henk Overbeek and Bastiaan van Apeldoorn (Eds.) Neoliberalism in Crisis, New York: Palgrave Macmillan, 138-160.

Piketty, Thomas (2015), Yirmibirinci Yüzyılda Kapital, (Çev. Hande Koçak), İstanbul: Türkiye İş Bankası Kültür Yayınları.

Rozanov, Andrew (2005), "Who Holds the Wealth of Nations". Central Banking Journal, 15(4), 52-57.

Schwartz, Herman (2012), "Political Capitalism and the Rise of Sovereign Wealth Funds", Globalizations, 9(4), 517-530.

Sun, Xiaolei, Li Jianping, Wang, Yongfeng, Clark, Woodrow (2014), "China's Sovereign Wealth Funds' Investments in Overseas Energy: The Energy Security Perspective”, Energy Policy, 65, 654-661. 
Sovereign Investment Lab. (2016), The Sky Did Not Fall. Sovereign Wealth Fund Annual Report.

SWF Institute, http://www.swfinstitute.org/

Şimşek, Orhan (2016), “Çin Küreselleşmesinin Siyasal İktisadı: Devlet Mülkiyetli Şirketler Üzerinden Bir İnceleme”, içinde İsmail Şiriner, Julia Dobreva ve Çiğdem Boz (Eds.) Political Economy of Globalization: Financialization and Crises. Istanbul: IJOPEC Publication, 103-113.

ten Brink, Tobias (2010), “The Challenges of China's Non-Liberal Capitalism for the Liberal Global Economic Order", Harvard Asia Quarterly, 36-44. 